\title{
ESTUDO GERAL SOBRE O INFINITO E A PROPAGAÇÃO DE ONDAS
}

\section{ARTIGO ORIGINAL}

BELLAS, Leonardo Dias ${ }^{1}$

BELLAS, Leonardo Dias. Estudo Geral sobre o Infinito e a Propagação de Ondas. Revista Científica Multidisciplinar Núcleo do Conhecimento. Ano 05, Ed. 11, Vol. 18, pp. 36-63. Novembro de 2020. ISSN: 2448-0959, Link de acesso:https://www.nucleodoconhecimento.com.br/fisica/propagacao-de-ondas

\section{RESUMO}

Este estudo propõe um melhor entendimento a respeito do Infinito e a relação com a propagação de ondas, seguido em realizar alguns questionamentos sobre todos os gráficos em pesquisa de propagação de ondas e propor novas soluções a respeito do tema, fazendo um estudo geral a respeito do Infinito, para posteriormente identificar sua relação com a propagação de ondas. O problema que vamos discutir aqui são razões e referencias matemáticas e físicas atuais a respeito do infinito e a propagação de ondas. Tendo por objetivo atualizar os gráficos de pesquisa de propagação de ondas, como uma nova maneira de observar e discutir a respeito do infinito. Para executar esse trabalho foram realizadas observações lógicas, matemáticas e físicas, comprovadas através de demonstrações e gráficos. O significado das informações desse estudo é melhorar o conceito para a observação das propagações de ondas eletromagnéticas.

Palavra-Chave: Infinito, propagação ondas.

\section{INTRODUÇÃO}

Foi realizado uma observação científica física em 2011 a respeito do Infinito e a propagação de ondas, e a partir das informações que puderam ser compreendidas,

${ }^{1}$ Graduado em Administração de Empresas com Habilitação em Comércio Exterior. 
foi realizado este estudo para serem feitos alguns questionamentos como, por exemplo, uma citação em pesquisas na internet que as ondas se propagam "Perpendicularmente ou Transversalmente", sendo assim essa citação será questionada e através de observações e algumas evidências, será proposto uma nova metodologia de como observar as ondas e as razões do Infinito. Através desse estudo abaixo, será demonstradas com os exemplos técnicos, através da aplicação de figuras/gráficos e com observações lógicas, matemáticas e físicas demonstrar as afirmações aqui realizadas.

\section{DEFINIÇÃO DE INFINITO EM PESQUISAS}

Definição de infinito na Internet:

É um conceito usado em vários campos, comoa matemática, filosofia e a teologia. É representado com o símbolo $\infty$, e na matemática é uma noção quase-numérica usada em proposições. Distingue-se entre infinito potencial e infinito atual. Mas é na matemática que o conceito tem as suas raízes mais profundas, sendo a disciplina que mais contribuiu para a sua compreensão. (Maor, Eli (1991). To infinity and beyond)

DEFINIÇÃO [infinito] ADJETIVO

que não tem limite; infindo

imenso; incalculável, imensurável

caráter do que é ou parece ser ilimitado

grandeza cujos valores não são limitados

aquilo que não tem limites, por poder vir a ser ou ser atualmente maior que qualquer quantidade dada de mesma natureza

Deus; a noção de divindade; o que transcende o entendimento humano menos us. que infinitivo

infinito que, no processo de limite, toma valores negativos

infinito que, no processo de limite, toma valores positivos. (BING, online, $\mathrm{s} / \mathrm{p})$ 


\section{DESENVOLVIMENTO DA TESE}

Agora iremos fazer uma pergunta para desenvolver essa Tese. Quantos Infinitos existem? A resposta correta para essa pergunta é:

Existem 2 Infinitos. Existem duas razões para Infinito observáveis, sendo uma distinta da outra.

Agora como observar ou identificar os dois infinitos? Vamos usar a matemática para observá-los. Por exemplo, vamos visualizar o zero ou neutro para que assim possamos encontrar os 2 Infinitos. Segue a lógica abaixo dos números Inteiros:

$-\infty,-9,-8,-7,-6,-5,-4,-3,-2,-1-0+1,+2,+3,+4,+5,+6,+7,+8,+9,+\infty$

Uma resposta mais completa como se observa acima, é que existem 2 Infinitos, podese contar 2 Infinitos. (Um Infinito ao lado direito positivo e outro Infinito ao lado esquerdo negativo, um distinto do outro), tanto aplicado na matemática quanto aplicado na física que posteriormente será explicado melhor. Existem duas razões distintas para definir um infinito. Uma razão, sentido ou força negativa e outra razão, sentido ou força positiva.

Então o zero é neutro no centro e sempre entre o negativo e positivo, tornando possível ir ao infinito negativo do lado esquerdo e ao infinito positivo ao lado direito.

E observando esses dois infinitos podemos identificar que o Infinito Negativo é oposto ao Infinito positivo, tanto visualizando na matemática quanto na física, eles estão expostos observáveis opostos um ao outro. Por exemplo, na matemática dos números inteiros, o (-1) um negativo está localizado opostamente ao (1+) um positivo, o (-2) dois negativo esta localizado opostamente ao (2+) dois positivo, e assim sucessivamente até chegar ao infinito de cada lado, o Infinito negativo e o Infinito positivo estão localizados opostamente um ao outro. Negativo esquerdo e positivo direito. E o Neutro sempre no meio, entre o negativo e o positivo.

Assim podemos calcular com o infinito também, por exemplo: 
$2+2=4$ (dois mais dois, igual a quatro)

$2-2=0$ (dois menos dois, igual a zero)

$3-3=0$ (três menos três, igual a zero)

$\infty-\infty=0$ (um infinito menos um infinito, igual a zero)

Então na matemática ao subtrairmos o infinito positivo através do infinito negativo o resultado será igual a zero.

Os infinitos negativos e positivos são oposto, matematicamente observável e fisicamente observável também, como será explicado nesse estudo.

Iremos aplicar na física. Visualizando o gráfico abaixo iremos observar e assim, podemos relacionar e identificar a lógica dos números inteiros, do infinito negativo e do infinito positivo, aplicado em um circuito básico de uma bateria comum (Pilha). Observamos que as pilhas possuem dois pólos, um pólo negativo e outro pólo positivo em sentidos opostos assim como os números inteiros. O pólo negativo em um sentido e direção oposto ao pólo positivo.

As duas forças de propagação das ondas eletromagnéticas são opostas. Negativo da direita para a esquerda, e positivo da esquerda para a direita, o pólo negativo tem um sentido negativo e o pólo positivo tem um sentido positivo, expressados e observados tanto na lógica dos números inteiros quanto no circuito básico de uma bateria comum. Como segue o gráfico abaixo:

Gráfico 1: relação números inteiros, negativo/positivo, bateria comum. 


\section{Fireuito lóniren bateria simples}

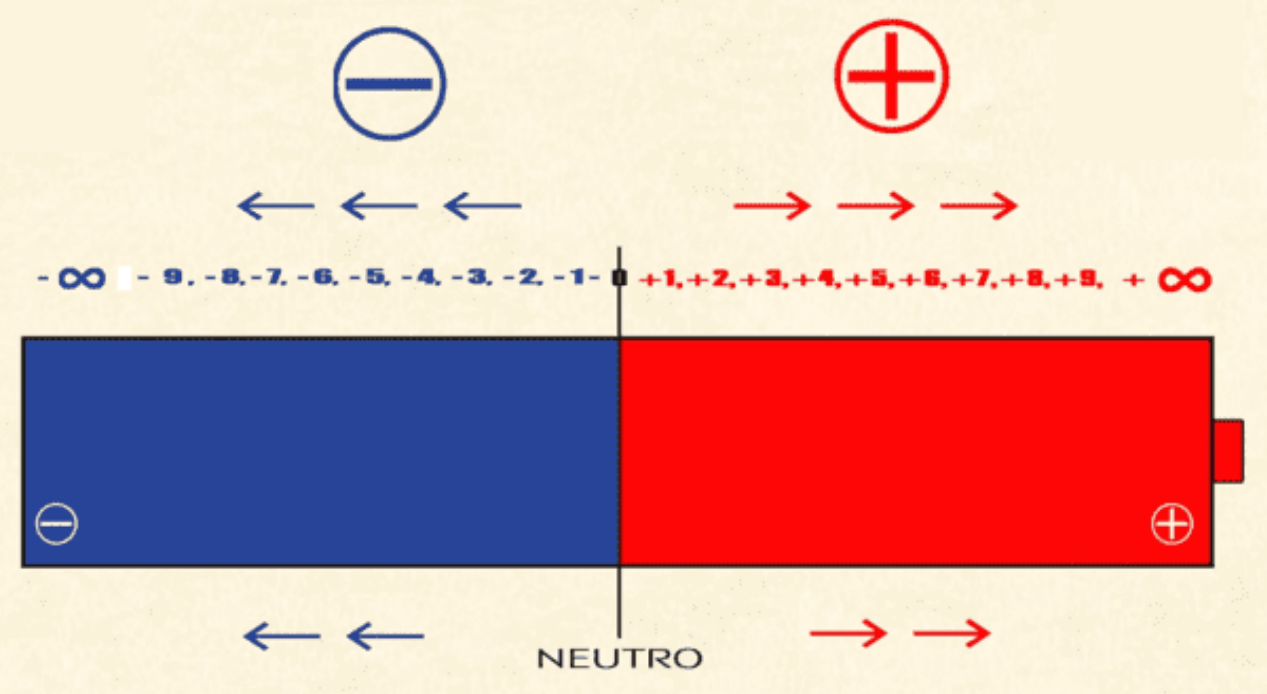

Fonte: Autor.

Conforme se visualiza no gráfico segue as informações abaixo a respeito das raízes negativas e positivas:

Esquerdo $=$ Negativo $/$ Direito $=$ Positivo

Infinito Negativo / Infinito Positivo

Esquerdo infinito / Direito infinito

Pólo negativo / pólo positivo

Onda ou pólo Negativo = Sentido Negativo / Onda ou pólo Positivo = Sentido Positivo .

Sentido matemático dos números negativos igual a centro esquerdo / Sentido matemático dos números positivos, igual centro direito. 
Força de propagação Onda Negativa = Direita para Esquerda / Força de Propagação Onda Positiva = Esquerda para Direita

O Neutro é no meio entre o Negativo e o Positivo tanto aplicado e visualizado no gráfico na matemática básica dos números inteiros, quanto no circuito físico da bateria, como podemos assim observar no gráfico. Na matemática e na física sempre entre o negativo e positivo existe o neutro.

E também tanto faz para qual posição você vire ou gire a pilha, o negativo sempre estará opostamente ao positivo e vice versa.

E como exposto na figura acima esses conceitos de observações lógicas podem ser aplicados tanto na matemática básica dos números inteiros, quanto em circuitos físicos de baterias e circuitos em geral, assim também podemos relacionar quanto à propagação de ondas, pois as ondas se propagam através de duas ondas eletromagnéticas, uma onda negativa e outra onda positiva que são opostas.

Agora serão dados exemplos de gráficos na internet sobre como as ondas eletromagnéticas se propagam, e posteriormente será proposto um novo conceito ou exemplo de como as ondas se propagam. Advertindo que todos os resultados dessa pesquisa na internet estão expressos equivocadamente e não condizem realmente graficamente como as ondas se propagam.

4. Gráficos de Propagação de Ondas em Pesquisas

Gráfico 2: propagação de ondas pesquisa internet. 


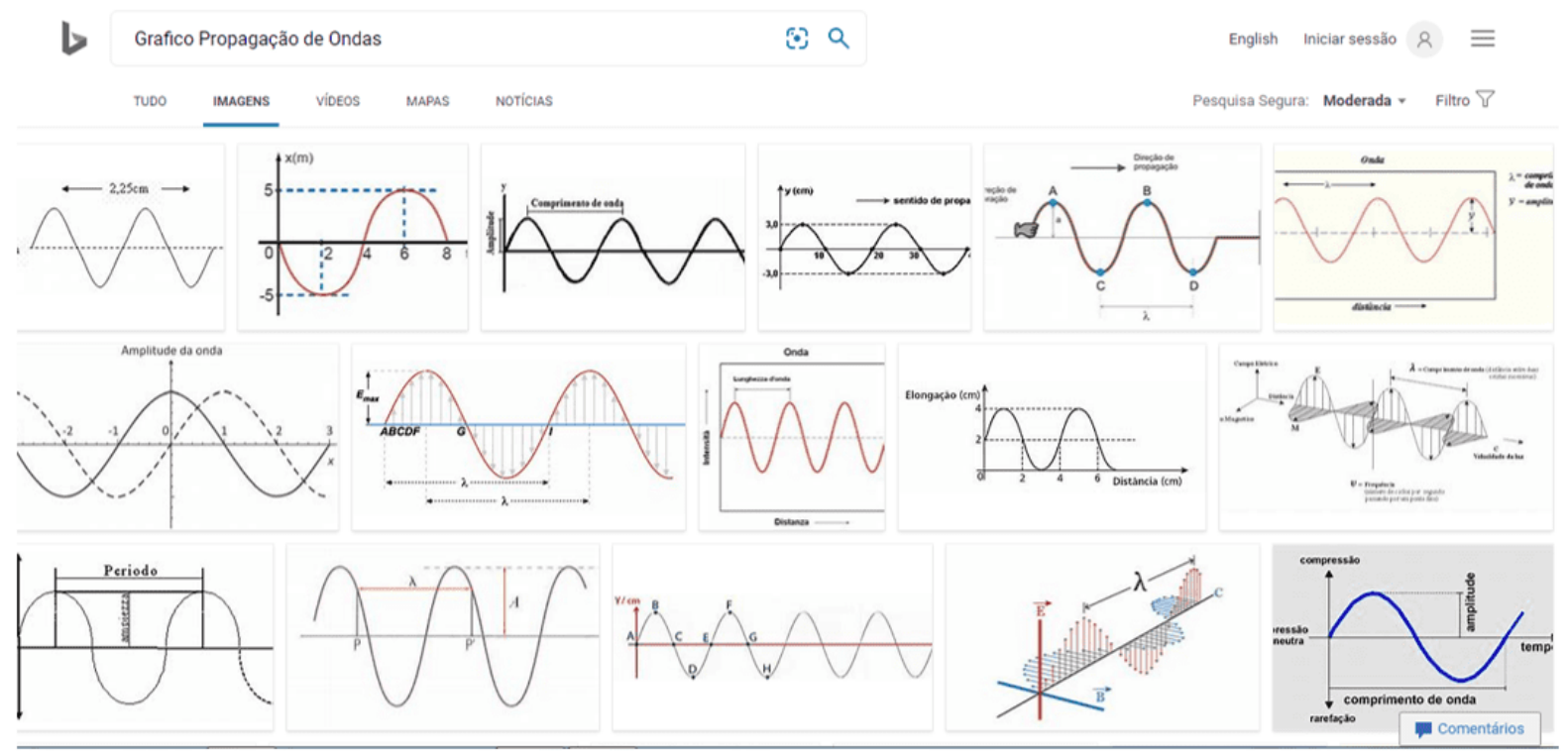

Fonte: internet Bing.

Gráfico 3: propagação de ondas pesquisa internet.

\ Grafico Propagação de 0... fơ Q

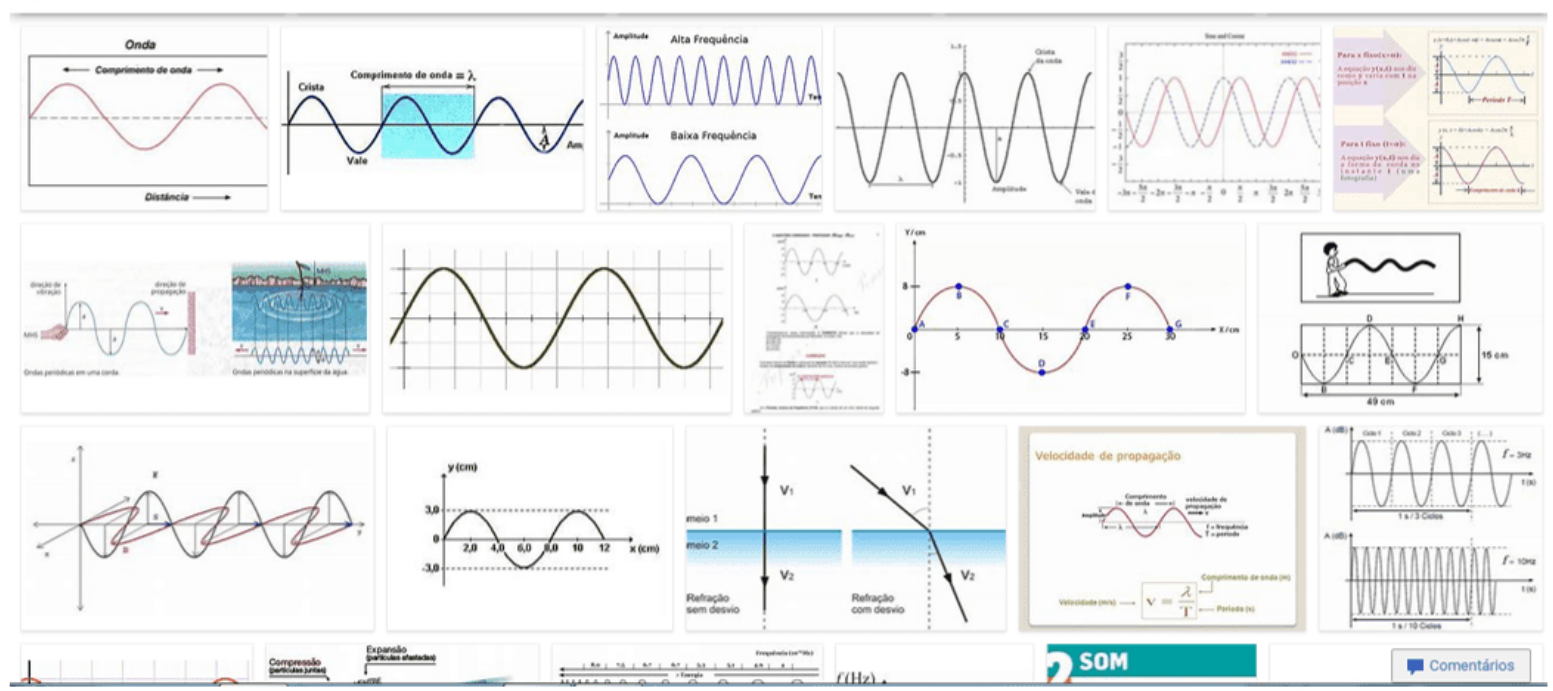

Fonte: Internet Bing.

Gráfico 4: propagação de ondas pesquisa internet. 


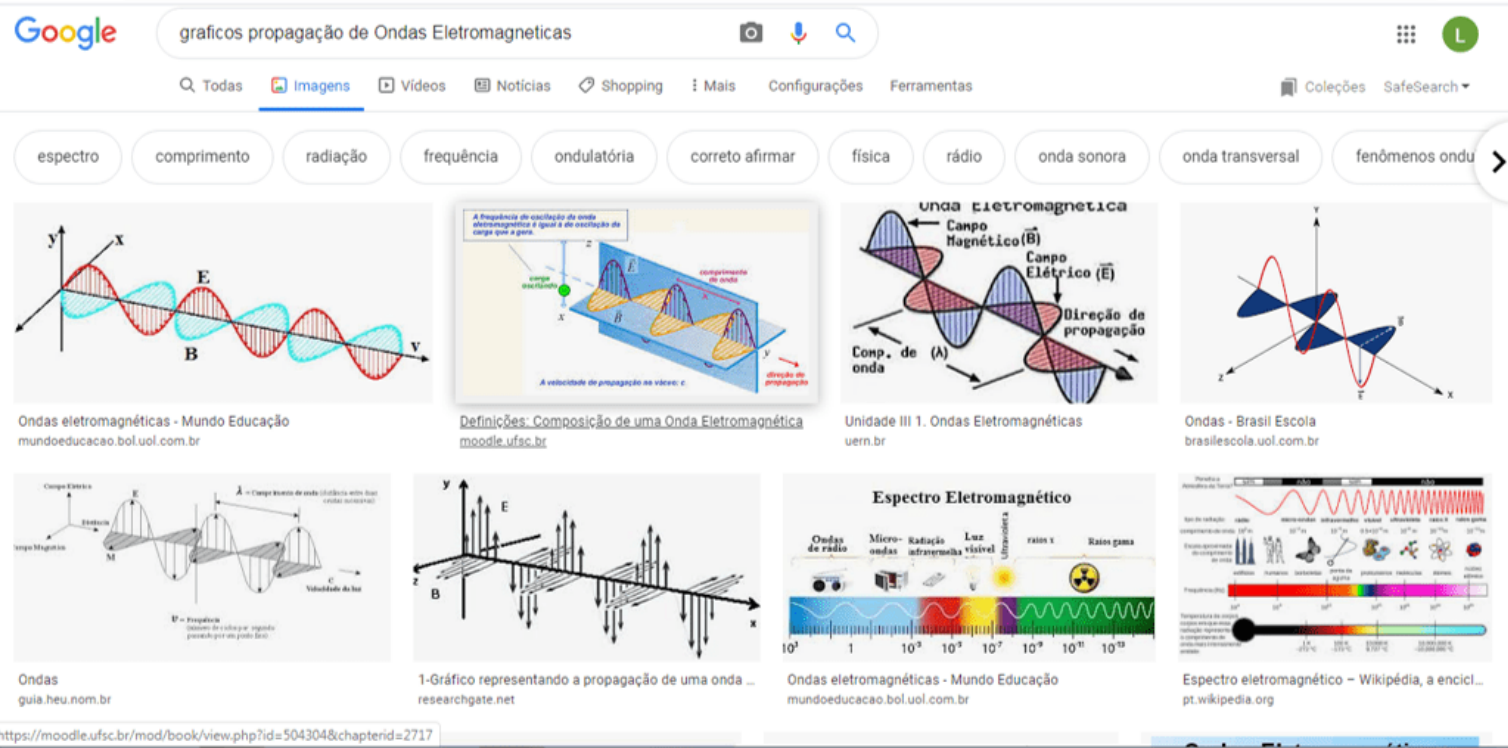

Fonte: internet Google.

Gráfico 5: propagação de ondas pesquisa internet.

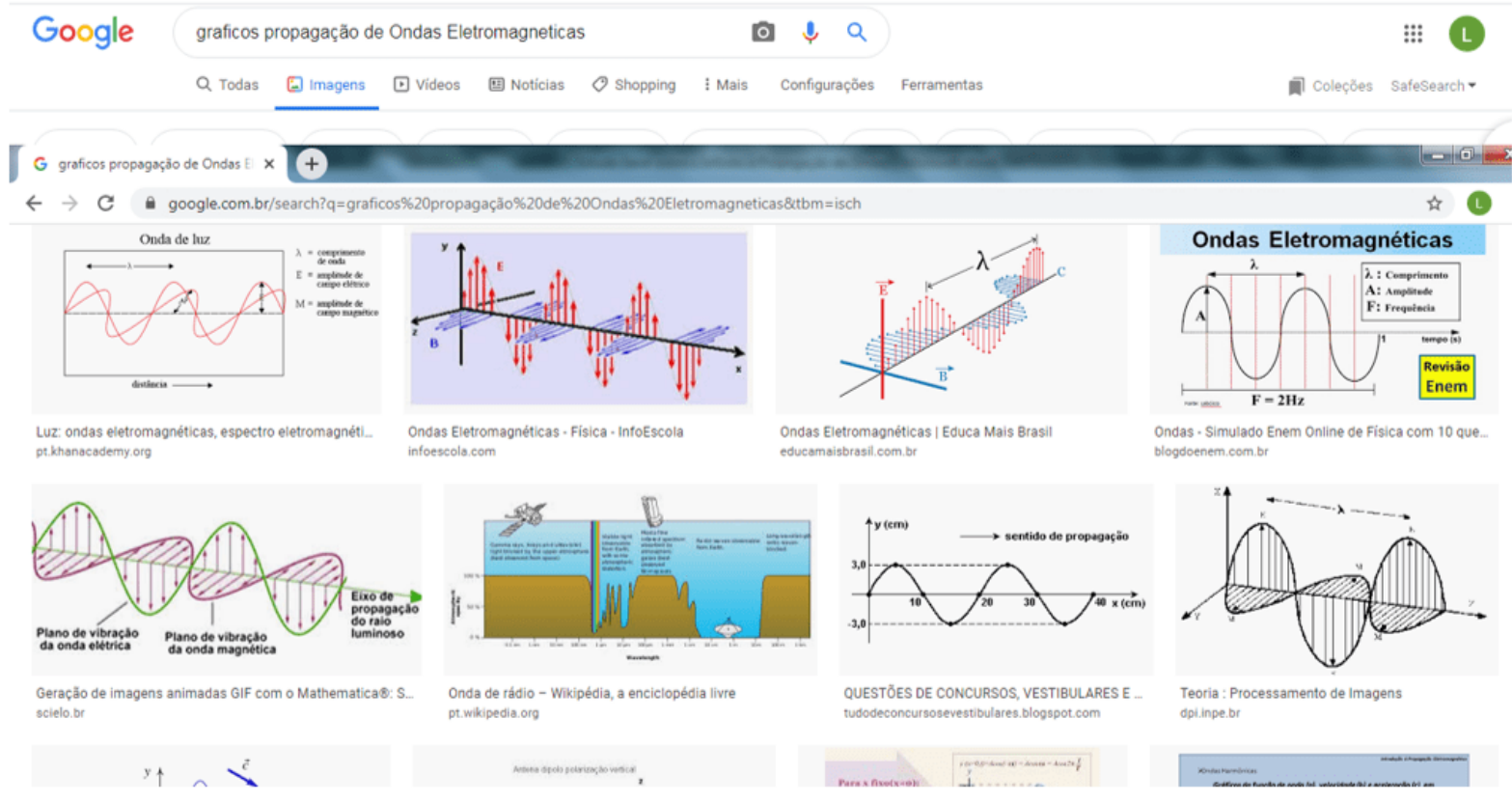

Fonte: internet Google.

Nesses gráficos de pesquisa na internet, a maioria deles apenas possui uma onda e um sentido de onda, e tem outros gráficos que possuem duas ondas, porém eles não identificam corretamente os sentidos das ondas, estão expressos graficamente de uma maneira que não condiz realmente.

RC: 65992

Disponível em: https://www.nucleodoconhecimento.com.br/fisica/propagacao-de-ondas 


\section{ANALISANDO AS DUAS ONDAS ELETROMAGNÉTICAS}

Foram realizadas pesquisas a respeito de propagação de ondas, uma das primeiras citações que aparece como pesquisa de definição de propagação de ondas na internet é essa:

O que são ondas eletromagnéticas?

Uma onda eletromagnética é formada por campos elétricos e magnéticos oscilantes e perpendiculares entre si. A direção de propagação da onda eletromagnética, por sua vez, é perpendicular (ângulo de 90º) aos vetores de campo elétrico e magnético.

Devido ao ângulo formado entre a perturbação e a direção de propagação, as ondas eletromagnéticas são caracterizadas como transversais. Como todas as ondas, podem transferir energia entre diferentes pontos do espaço, mas fazem-no sem que haja qualquer transporte de matéria, uma vez que não são capazes disso.

As ondas eletromagnéticas apresentam como características: comprimento de onda, velocidade de propagação, amplitude e frequência, e são passíveis de sofrer qualquer tipo de fenômeno ondulatório conhecido, tais como reflexão, refração, polarização, difração, espalhamento, absorção e interferência.(HELERBROCK, online, $s / p$ )

Gráfico 6: pesquisa internet 


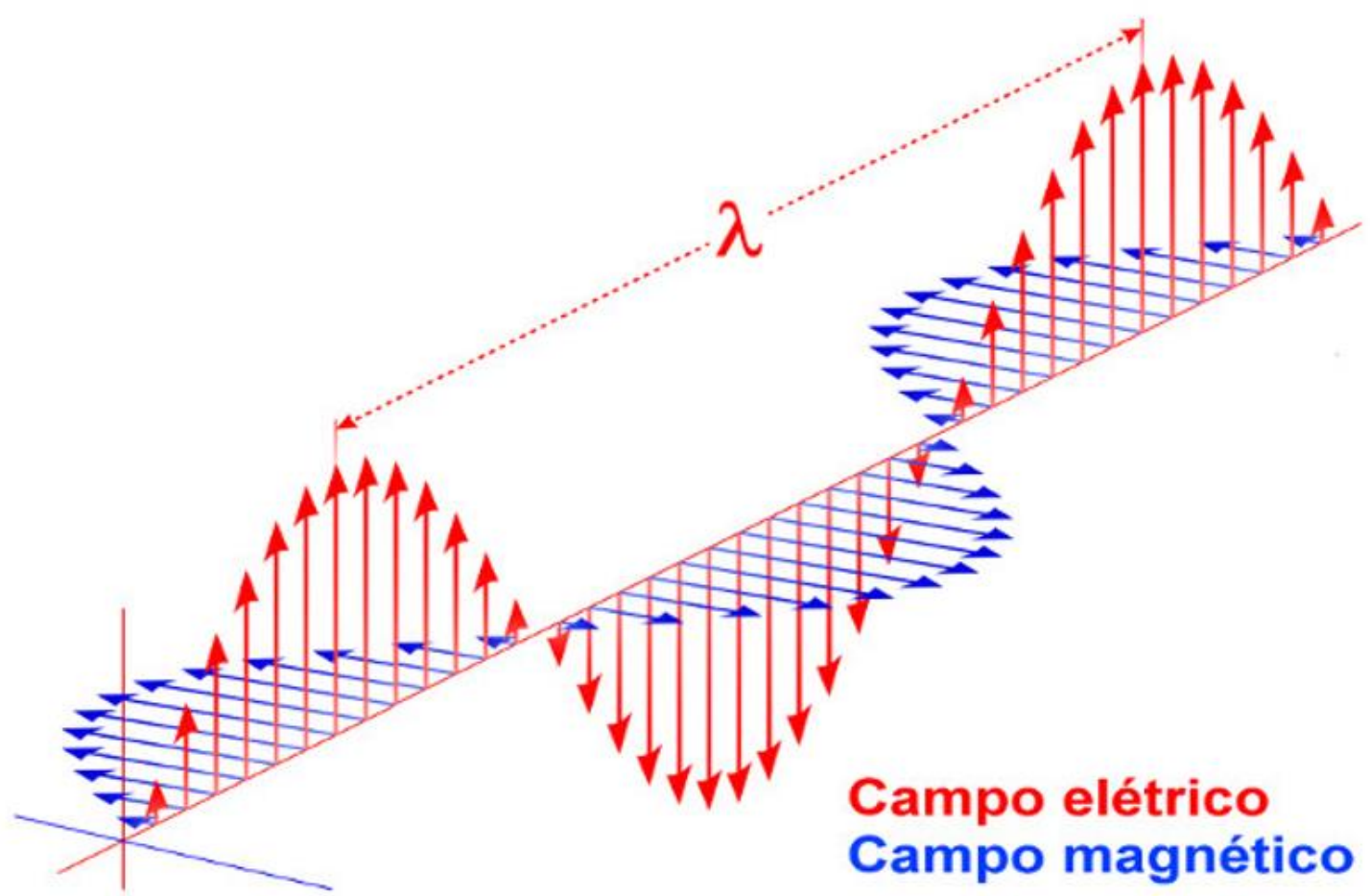

Fonte: Mundo educação Uol.

$\mathrm{Na}$ verdade, essa citação eles falam que as ondas são "perpendiculares ou caracterizadas como transversais", mas não, as ondas negativas e positivas não são perpendiculares, elas são opostas. Neste estudo está sendo proposto que uma onda negativa tem um sentido negativo diferente da onda positiva que tem um sentido positivo, elas são duas ondas distintas opostas uma da outra. Onda negativa no sentido negativo oposto a onda positiva que tem seu sentido positivo.

As ondas não se misturam nem se cruzam, uma onda é diferente da outra, e cada onda possuí sua finalidade especifica, o que é negativo sempre vai ser uma razão, campo ou força negativa e o que é positivo sempre vai ser uma razão, campo ou força positiva.

Por exemplo, em um imã podemos observar esses dois campos ou forças, elas se repelem ou se atraem, se você tentar conectar o positivo de um imã no positivo de outro imã, eles se repelem, que é o mesmo caso se você tentar conectar o negativo com o negativo, eles vão se repelir também. Tem que encaixar o positivo no negativo para os pólos do imã se atrair e conectarem, uma onda ou força é só negativa e a 
outra onda ou força é só positiva. Duas ondas diferentes uma da outra. O lado esquerdo negativo do imã tem uma freqüência, campo, força, e razão negativa e o lado direito positivo do Imã tem uma freqüência, campo, força e razão positiva.

Números inteiros Infinitos, ondas, pólos, circuitos, sistemas lógicos, baterias, imãs, inclusive no gráfico de propagação de ondas em todos os exemplos e conceitos em que podemos aplicar o negativo e positivo, são duas razões distintas, sendo sempre o negativo oposto ao positivo. E posteriormente será aplicado com mais observações lógicas de como o negativo oposto ao positivo se comportam.

Uma frase famosa que existe onde pode ser aplicado o negativo e positivo é os "Opostos se atraem", isso é uma afirmação que existe duas razões distintas, uma negativa e outra positiva, que opostamente se atraem, um exemplo dado aqui é o imã. As duas energias infinitas opostas dos imãs se atraem.

A existência dessas duas forças, negativas e positivas, são consideradas um fato.

O embasamento, ou o princípio que sustenta esse raciocínio é propor um conceito atualizado tanto dissertativo quanto gráfico para a observação de como as ondas se propagam, pois analisando esse conceito que esta sendo questionado de que as ondas são "transversais ou perpendiculares" é equivocado, inclusive graficamente.

Sendo assim observando e realizando a interpretação do gráfico acima que esta sendo contestado, em nessa análise, traz o entendimento de que as ondas se cruzam, e no exemplo desse gráfico, é como se onda positiva tivesse a direção vertical e a onda negativa tivesse a direção horizontal, sendo assim nesse caso elas seriam perpendiculares, elas se cruzariam, as ondas e os campos eletromagnéticos iriam se misturar, mas não, as ondas não se misturam e nem se cruzam, o que é negativo sempre vai ser negativo e o que é positivo sempre vai ser positivo, elas são apenas opostas, onda negativa em um sentido negativo e onda positiva em um sentido positiva, e tanto a onda negativa quanto a onda positiva são verticais e horizontais,

A intenção deste estudo é propor um conceito mais atualizado de que tanto a onda negativa quanto a onda positiva são verticais e horizontais, e a diferença entre as 
ondas é que elas são opostas e isso significa que a diferença entre as ondas é que uma onda negativa tem o sentido negativo e uma onda positiva tem um sentido positivo,

Sempre o negativo é oposto ao positivo podendo ser aplicado e observado em diversos tipos de conceitos e exemplos.

Mais a frente, este estudo irá propor um conceito de visualizar a propagação do som, deixando mais nítido como visualizar o comportamento ou a mecânica da propagação da onda eletromagnética negativa e da onda eletromagnética positiva durante a propagação do som. Será demonstrado com um exemplo gráfico que tanto a onda negativa quanto a positiva tem a direção vertical e horizontal, ou seja, as duas ondas se locomovem e se propagam de baixo para cima e da direita para esquerda, e sempre a onda negativa no sentido negativo e a onda positiva no sentido positivo. Existem dois campos eletromagnéticos distintos, relacionando o negativo oposto ao positivo.

Em resumo as ondas eletromagnéticas se propagam através de duas ondas distintas infinitas opostas, uma onda negativa no sentido negativo e outra onda positiva no sentido positivo.

Vamos diferenciar uma onda da outra. A onda positiva no sentido positivo se locomove da esquerda para direita. E a onda negativa no sentido negativo se locomove da direita para esquerda. As duas ondas se propagam em sentidos opostos, baseado na lógica dos números inteiros e no circuito comum de uma bateria. Como se observa corretamente no gráfico abaixo.

\section{GRÁFICOS DE PROPAGAÇÕES DE ONDAS}

Gráfico 7: correto de propagação de ondas: 


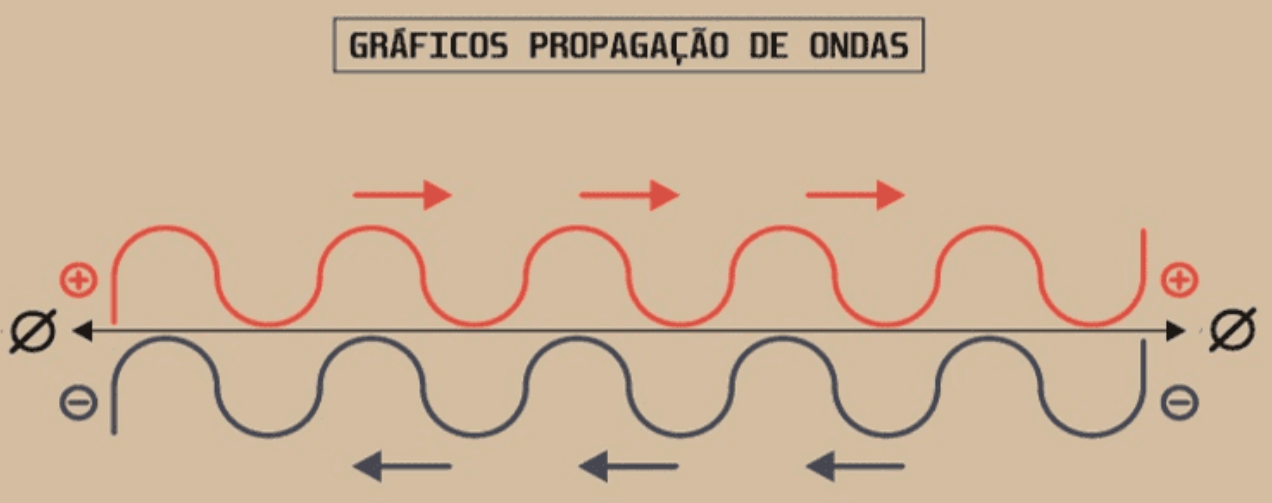

Fonte: Autor.

Segue outra forma básica de expressar o gráfico de propagação de ondas:

Gráfico 8: propagação de ondas. 


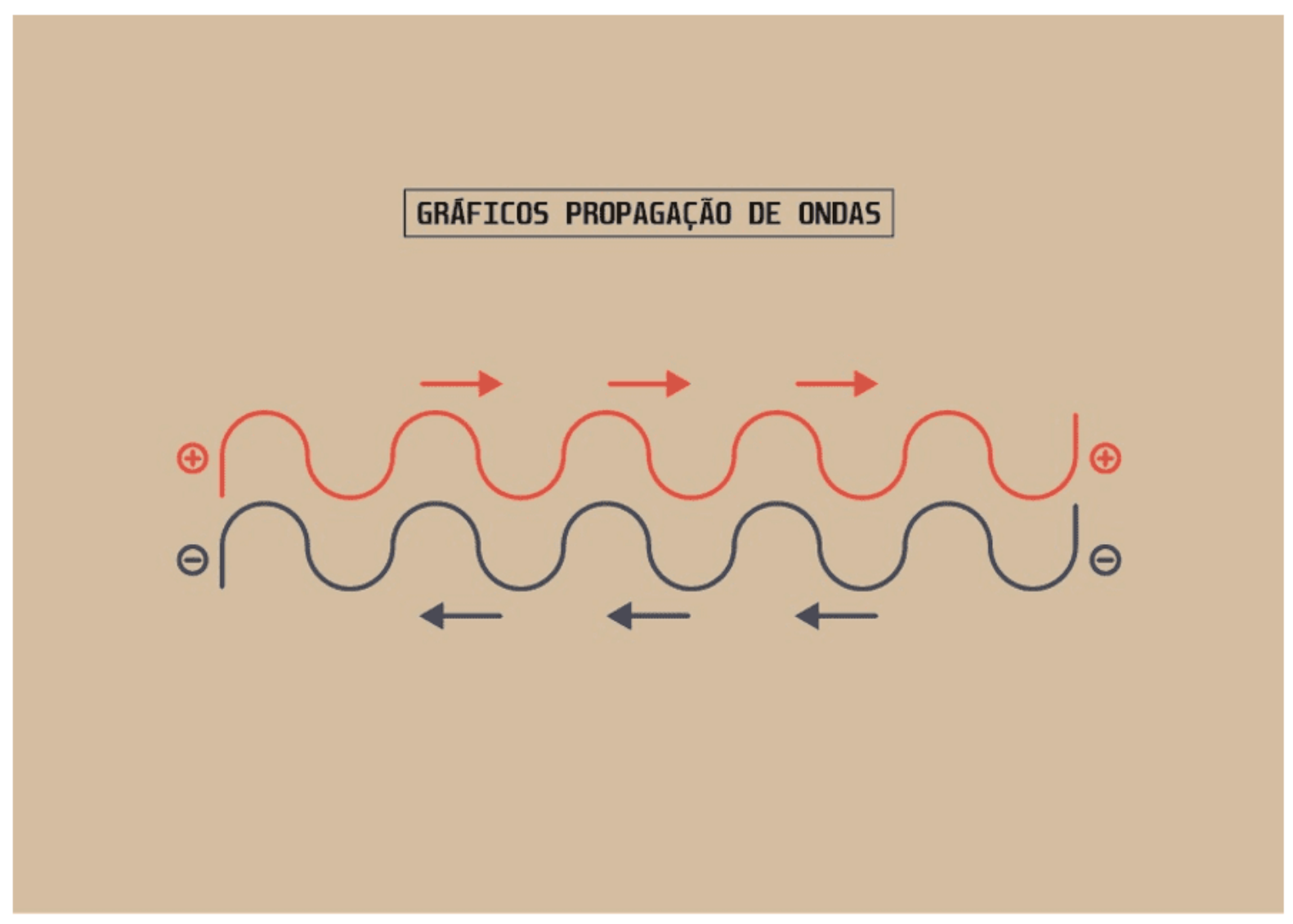

Fonte: Autor.

E como podemos observar nos gráficos, 7 e 8 acima é que existem duas ondas, uma onda negativa no sentido negativo e uma outra onda positiva no sentido positivo.

Podemos também relacionar o gráfico correto de propagação de ondas com o circuito básico de uma bateria comum e em ambos os exemplos o negativo é oposto ao positivo, negativo igual a sentido negativo e positivo igual a sentido positivo, e o que é negativo sempre vai permanecer negativo e o que é positivo sempre vai permanecer positivo, como segue exemplificado abaixo:

Gráfico 9: Relação bateria comum com gráfico propagação de ondas.. 


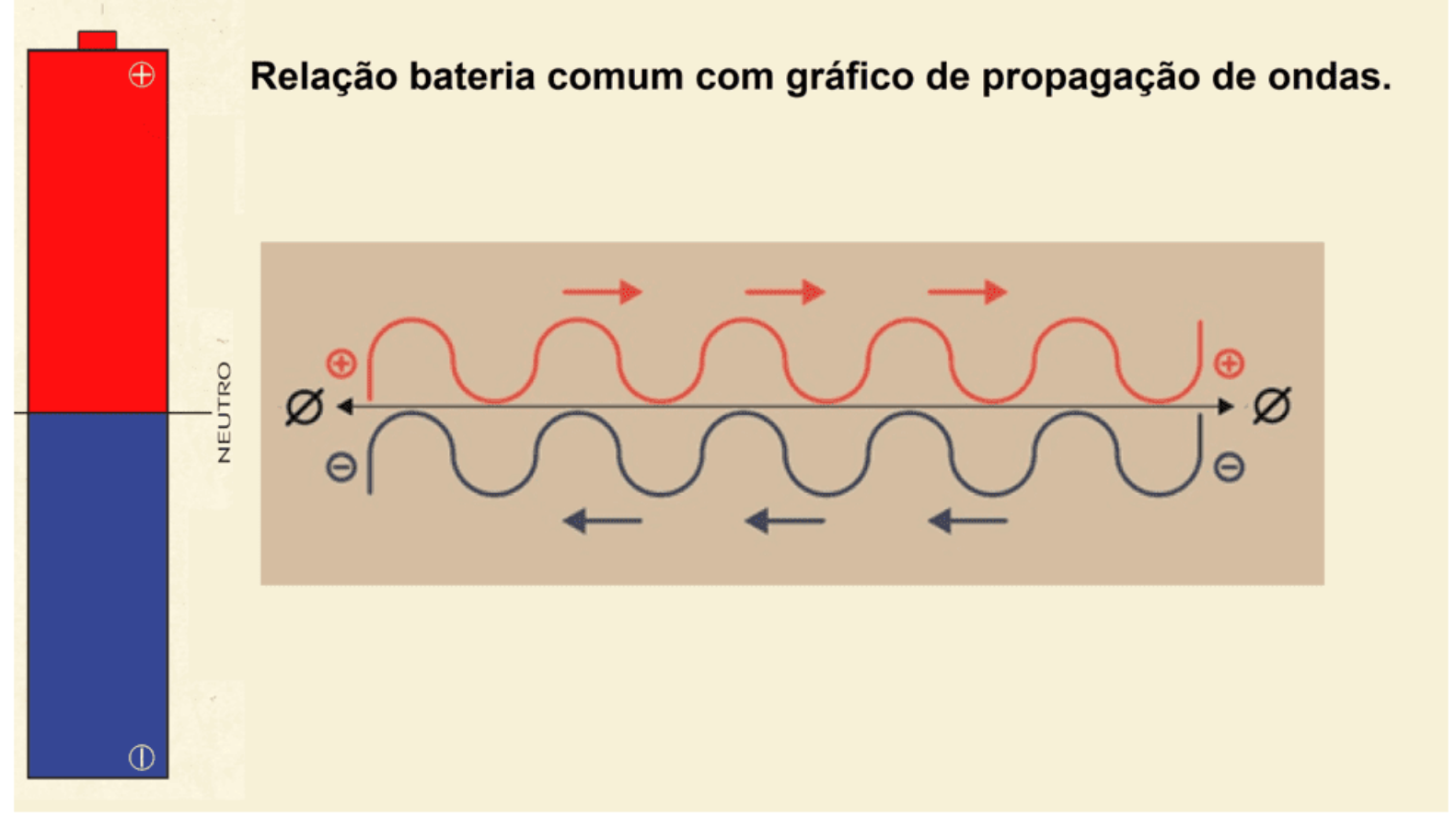

Fonte: Autor.

Observando o gráfico acima tanto no circuito de uma bateria comum quanto no gráfico de propagação de ondas, existem um pólo ou onda negativa no sentido negativo e outro pólo ou onda positiva no sentido positivo.

Aplicando-se no eixo $X$ e Y. O eixo $X$ é o tamanho da onda e o eixo $Y$ é o comprimento da onda. $O$ eixo $X$ define o tamanho da propagação da onda ou seu raio e diâmetro. $\mathrm{O}$ eixo $\mathrm{Y}$ vai ser definido pela altura da onda, ou sua freqüência, por exemplo, se é uma micro onda ou uma macro onda.

Gráfico 10: eixo x e y. 


\section{GRÁFICO EIXO X \& Y}

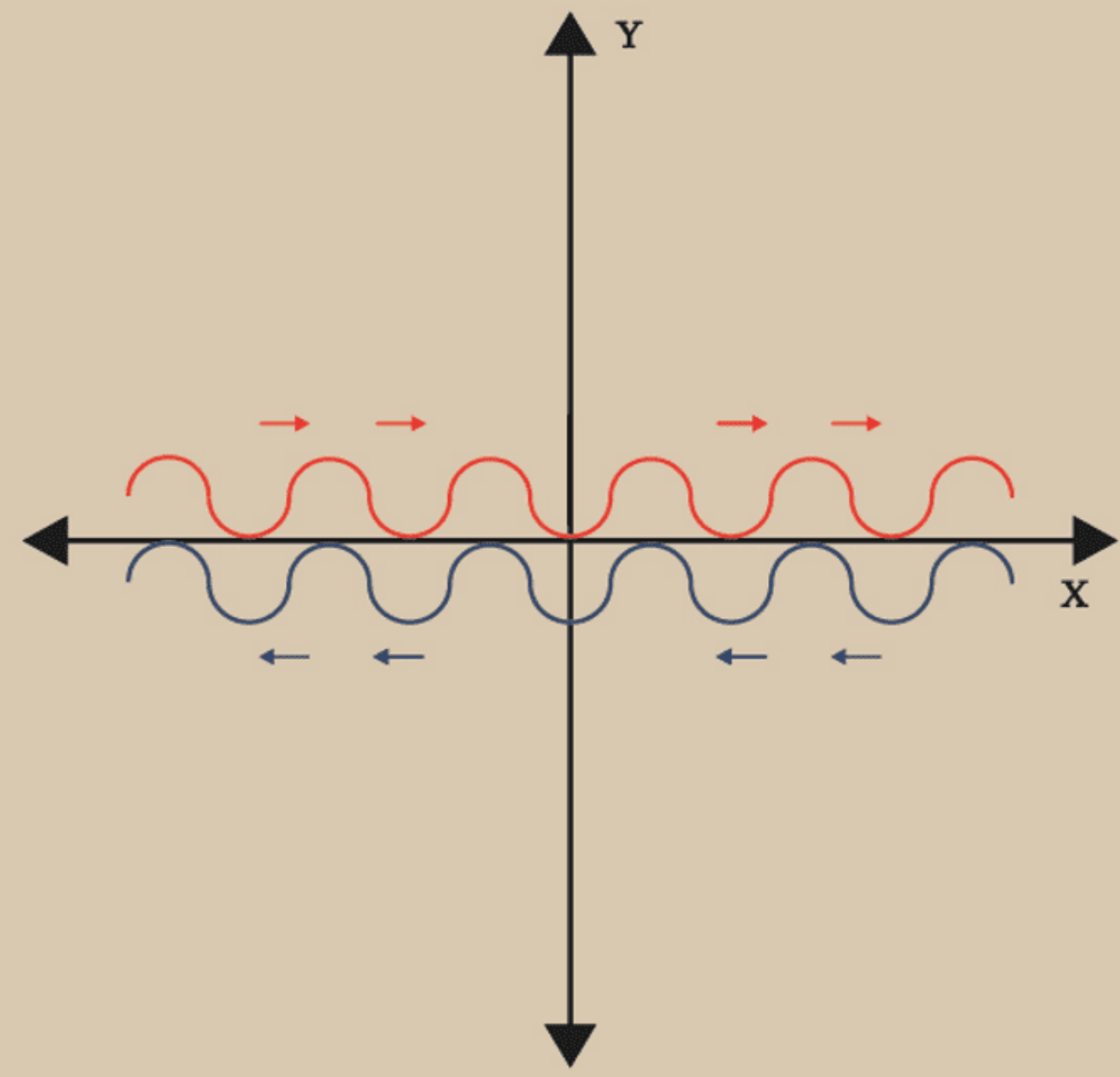

Fonte: Autor.

\section{APLICAÇÕES DO INFINITO EM PROPARGAÇÃO DE ONDAS}

1 - Pode-se também aplicar esse gráfico correto em nosso cotidiano. Por exemplo, um controle remoto de TV comum. Existem duas pilhas. Uma pilha tem que estar na posição positiva e a outra pilha têm que estar na posição negativa, em sentidos 
opostos. Para que assim feche o circuito e o controle funcione corretamente, se as duas pilhas estiverem na mesma posição o circuito não funciona, e se a onda negativa não fosse oposta a onda positiva, o controle remoto funcionária com as duas pilhas na mesma posição de sentido, mas não, para o controle funcionar, as pilhas têm que estar em posições opostas uma à outra, respeitando o sentido das ondas, pois as ondas eletromagnéticas se propagam em sentidos opostos. Negativa da direita para esquerda e positiva da esquerda para direita. Dois pólos ou duas ondas, uma onda é diferente da outra. Uma onda oposta a outra. Nesse exemplo do controle remoto, conseguimos observar nitidamente o sentido das ondas, uma onda negativa no sentido negativo e outra onda positiva no sentido positivo. Comprovando que a onda negativa é oposta a onda positiva. Conforme segue o gráfico abaixo.

Gráfico 11: controle remoto:

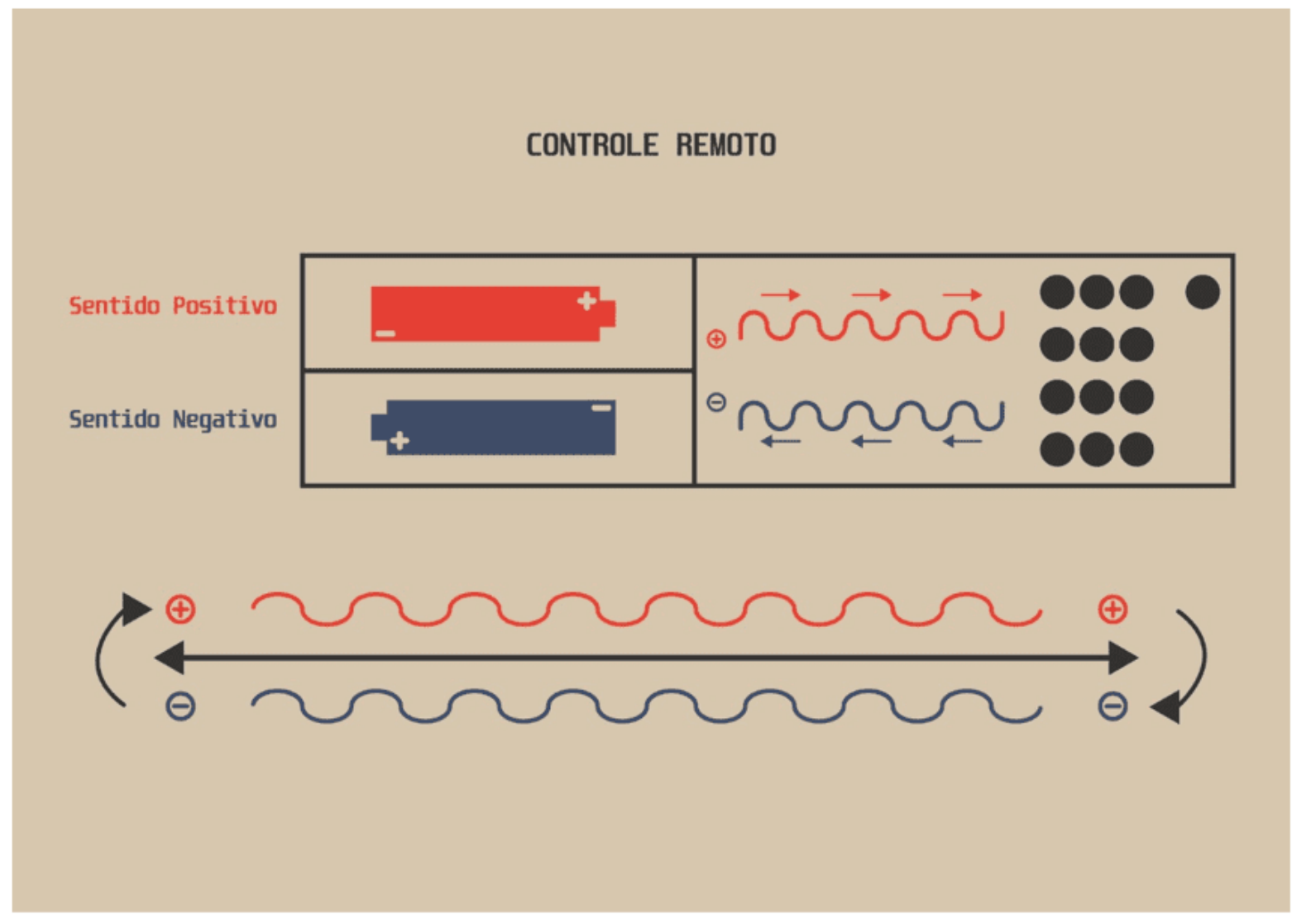

Fonte: Autor. 
2 - Vamos aplicar no que conhecemos. Vamos analisar uma silhueta humana nesse exemplo, mas poderia ser de qualquer simetria animal. $\mathrm{O}$ zero = neutro no centro. Ao lado esquerdo infinito negativo. Ao lado direito infinito positivo. Lado esquerdo = negativo. Lado direito = positivo. Assim temos um olho negativo e um olho positivo, um braço negativo e outro braço positivo, ou também as pernas, uma negativa e outra positiva. Assim possuímos características físicas tanto negativas quanto positivas e sempre o negativo lado esquerdo está ao oposto do positivo lado direito. Como no gráfico abaixo:

Gráfico 12: simetria. 


\section{SIMETRIA}

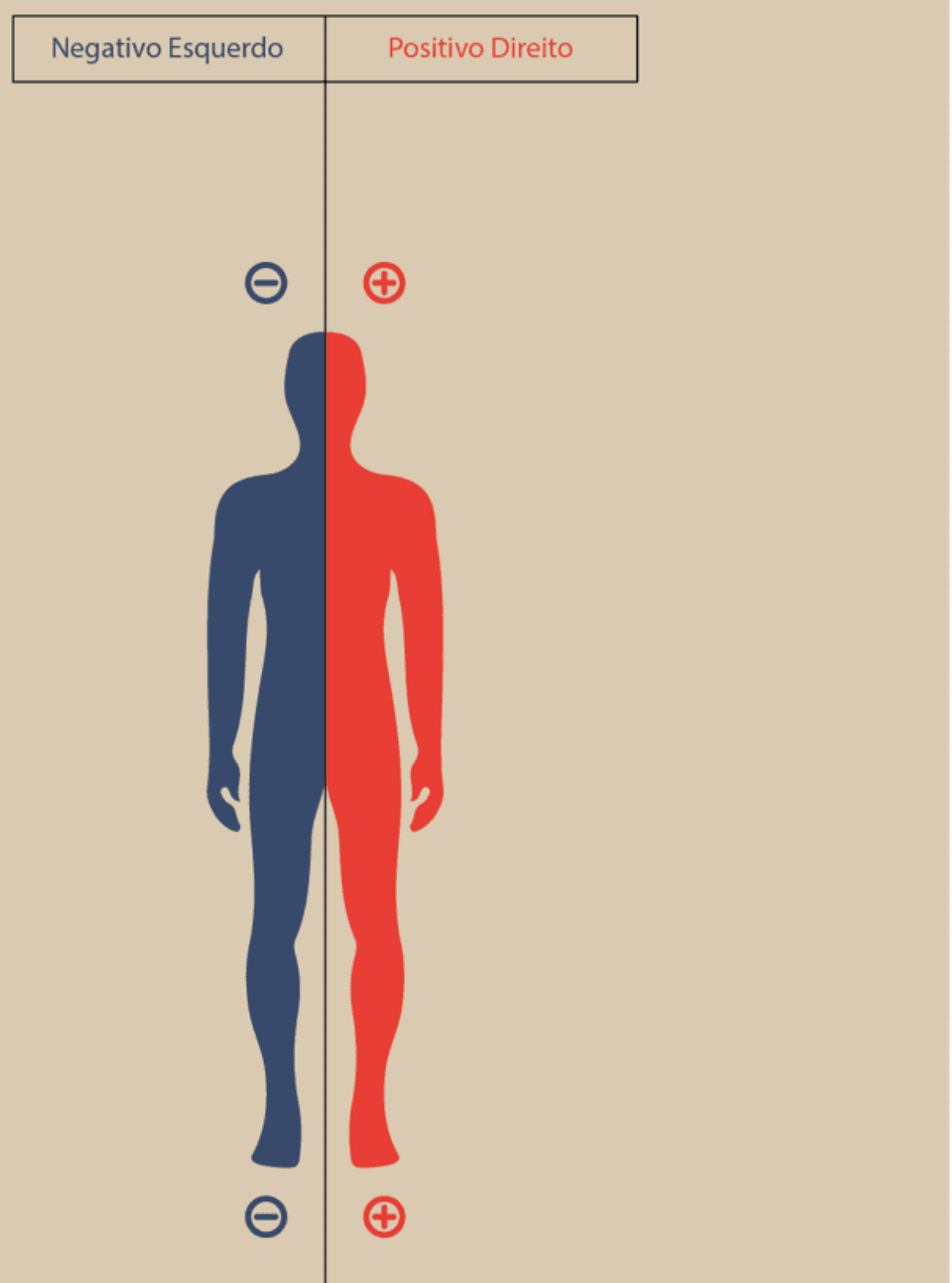

Fonte: Autor.

3 - As ondas eletromagnéticas se propagam infinitamente através de duas ondas, uma positiva e outra negativa em esferas eletromagnéticas. Em uma visão de esferas, as ondas se expandem e se propagam em todas as direções. Um círculo em 2 dimensões possui 360 Graus. Uma esfera possui 360 x 360 graus = 129.600 graus. Uma esfera 
em 3 dimensões possuí 129.600 graus, as duas ondas se propagam em todas a direções, com a força de propagação da onda positiva no sentido positivo, nesse caso horário, e a força de propagação da onda negativa no sentido negativo, anti-horário.

Um exemplo é o som, o som se propaga através de duas ondas eletromagnéticas uma onda eletromagnética positiva e outra onda eletromagnética negativa, a onda negativa no sentido negativo e a onda positiva no sentido positivo e em todas as direções, as duas ondas se propagam nas direções verticais e horizontais. $E$ as ondas não são "perpendiculares ou transversais".

Uma observação lógica e física aplicável de como o som ou a propagação do som, através de duas ondas, uma positiva e outra negativa ocorre, é por exemplo, quando uma pessoa esta no meio de uma sala de aula, em seu celular recebe uma ligação e toca uma música, com um volume auto ou audível, o som se propaga em todas direções possíveis, todas as pessoas ao redor no meio da sala irão ouvir tocar o celular. O som e as ondas se propagam em todas as direções, porém cada onda tem seu sentido específico, onda negativa no sentido negativo e onda positiva no sentido positivo.

A justificativa de que as ondas Negativas e Positivas se propagam em sentidos oposto e em todas as direções é como, por exemplo, você consegue ouvir uma caixa de som estando atrás dela, ou em cima e embaixo, ou também consegue ouvir ou conversar como uma pessoa com ela falando de costas para você, a vibração acontece para todas as direções, mas o som é uma vibração eletromagnética entre uma onda negativa e outra onda positiva. E aqui nesse estudo sendo identificado um sentido ou uma razão distinta para cada tipo de onda, uma razão e sentido negativo para a onda negativa e uma razão e sentido positivo para a onda positiva. O gráfico abaixo irá propor uma maneira mais afinada de como observar a propagação do som através de duas ondas eletromagnéticas.

A força de propagação é como se uma onda empurrasse a outra, por exemplo, a onda negativa empurra a onda positiva, e a onda positiva empurra a onda negativa, assim sucessivamente e consequentemente, se expandido e se propagando em todas as 
direções. Ocorre uma friç̧ão entre a onda positiva e a onda negativa. A onda positiva tem um sentido diferente da onda negativa, elas são opostas. Uma onda sentido positiva e outra onda sentido negativa, as duas ondas se propagam em todas as direções da rosa dos ventos, sempre uma onda em sentido oposta a outra onda.

Existem também campos ou camadas eletromagnéticas, um campo ou camada eletromagnética negativa e outro campo ou camada eletromagnética positiva e as ondas não se misturam, o que é negativo sempre vai permanecer negativo e o que é positivo sempre vai permanecer positivo. E essa afirmação de que as ondas não se misturam, podem ser observadas nas lógicas matemáticas dos números inteiros e também estão presentes em circuitos lógicos e físicos de baterias, nos circuitos em geral e nos circuitos dos Sistemas Binários, que será explicado e aplicado posteriormente, sendo assim também matematicamente o que é negativo sempre vai ser negativo, e o que é positivo sempre será positivo, e sempre o negativo estará opostamente ao positivo em todos os conceitos aplicáveis.

E nas ondas eletromagnéticas, as ondas negativas circulam e se propagam no sentido negativo, oposto as ondas positivas, que circulam e se propagam no sentido positivo.

Esse gráfico abaixo é como se você tivesse a perspectiva de visualizar a propagação do som de cima, como exemplo da sala de aula que aqui foi proposto, é como se você estive visualizando a propagação do som por uma perspectiva de cima da sala de aula:

Gráfico 13: propagação de ondas (Som) em esferas eletromagnéticas positivas e negativas. 


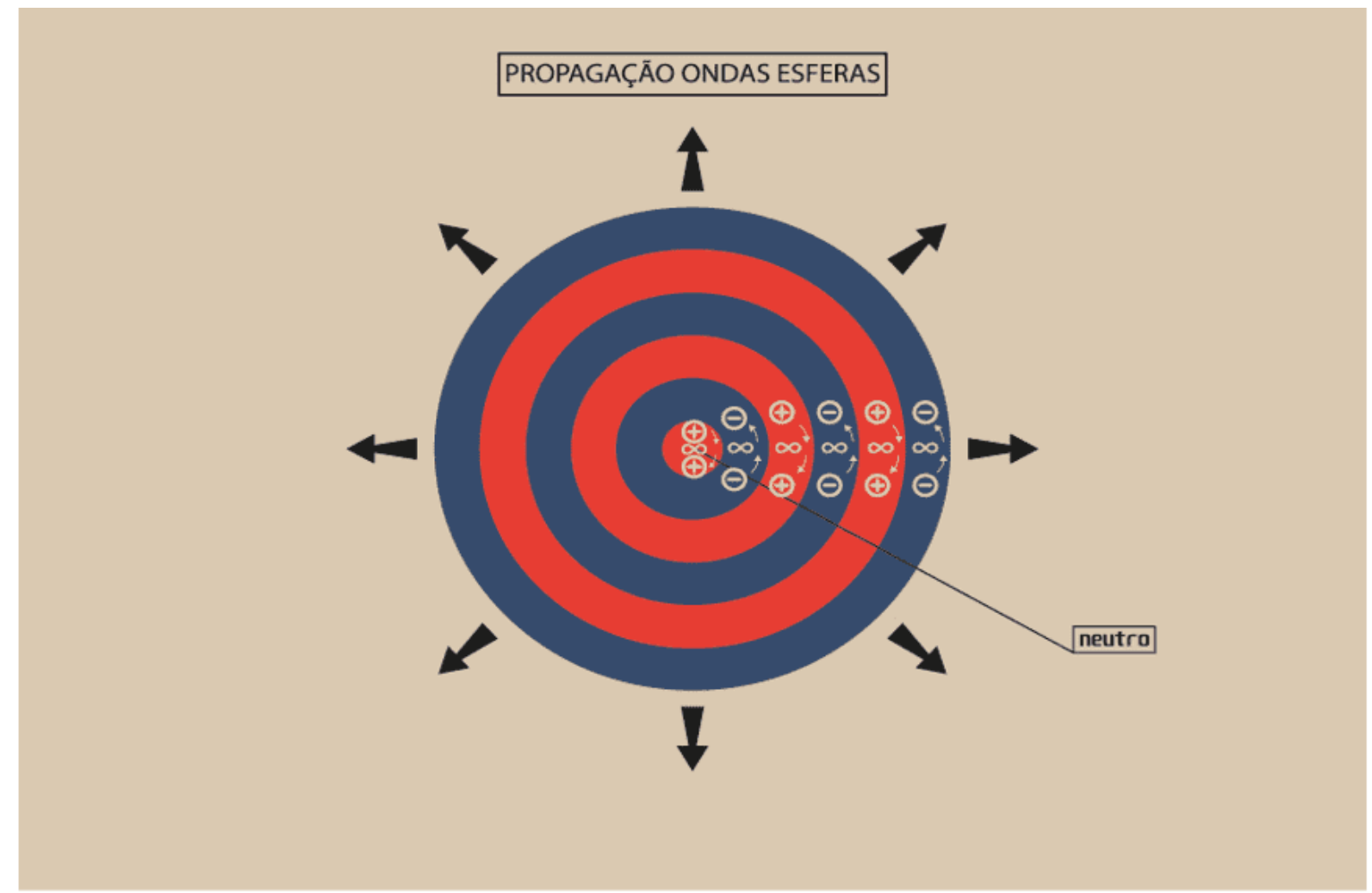

Fonte: Autor.

Assim podemos observar melhor nesse gráfico de propagação do som que as ondas não são "transversais ou perpendiculares", e que assim as ondas são opostas, as duas ondas se propagam em todas as direções, tanto vertical quanto horizontal e cada onda possuí seu sentido específico, a onda negativa igual ao sentido negativo e onda positiva igual ao sentido positivo.

4 - Sistemas Binários:

Há um tempo foi realizada uma descoberta científica de um novo Sistema Binário, esse estudo foi publicado nesta mesma revista científica e esta nas referências desse trabalho, mas os conhecimentos dessas duas razões do infinito e das informações a respeito de circuitos, de como as ondas eletromagnéticas se propagam e uma melhor forma de observação quântica de como o som se propaga, através de uma onda negativa e outra positiva, deu base e condições para realização da descoberta cientifica do sistema Binário 2. (BELLAS, L.D. Sistema Binário 2 - Código Fechado.) 
Além de ser um sistema, é um circuito eletromagnético e uma programação também, e tem em sua raiz a programação do negativo e do positivo binariamente, então se programa o negativo e positivo através do 0 (zeros) e 1 (uns), e o negativo é oposto ao positivo binariamente também, ou seja na programação e circuito binário o negativo é oposto ao positivo, o Sistema Binário é um circuito eletromagnético que funciona com o negativo e positivo, sendo assim isso é mais uma relação e confirmação de que as ondas se propagam em sentidos opostos e não transversais ou perpendiculares. Pois tanto as ondas como os circuitos são eletromagnéticos.

Mas quanto ao circuito, os conhecimentos presentes nesse estudo ajudaram a identificar diferenças técnicas entre os circuitos lógicos e eletromagnéticos do Sistema Binário 1 para o Sistema Binário 2 e que assim ajudaram a concretizar essa descoberta.

No desenvolvimento dos circuitos lógicos das programações dos Sistemas Binários, podemos identificar e relacionar o Negativo e o Positivo de diversos conceitos matemáticos, lógicos e físicos, neles também tem em sua raiz sempre o negativo oposto ao positivo, existem duas possibilidades e sempre antagônica, como segue esses exemplos abaixo:

1 - Negativo / Positivo (Circuito lógico físico)

2 - Falso / Verdadeiro

3 - Não / Sim

4 - Esquerdo / Direito

5 - Mínimo / Máximo

6 - Nada / Tudo

7 - Desligado / Ligado

8 - Ausência / Presença 
9 - Baixo / Alto

10 - Apagado / Aceso

$11--1+$ (Sinal menos e mais matemática)

$12-</>\quad$ (Sinal menor e maior matemática)

$13-\leq / \geq \quad$ (Sinal menor ou igual a e sinal maior ou igual a)

14 - Números inteiros negativos / Números inteiros positivos (Lógica matemática da programação do Sistema Binário 2)

15 - 0 / (Zero e Um, neste caso o zero é negativo, como acontece no Sistema Binário 1, mas dependo da disposição lógica da programação binária o zero pode funcionar como neutro também, assim como acontece no Sistema Binário 2)

A intenção das informações desse estudo é proporcionar uma nova visão, relacionando e aplicando o negativo e o positivo de diversas maneiras, assim como foi exposto com exemplos técnicos de lógicas, através de figuras e gráficos e nas informações aqui presentes, em todos os conceitos aqui relacionados e aplicados o negativo é oposto ao positivo e não é "perpendicular ou transversal" como foi questionado neste estudo.

\section{CONCLUSÕES}

Por aspectos lógicos e embasados na lógica das duas razões dos infinitos, uma negativa e outra positiva dos números inteiros, e na lógica dos circuitos eletromagnéticos que também funcionam com os negativos e positivos ambos opostos, as informações e o conhecimento presentes nesse estudo e em seus gráficos são mais atualizados e próximos da realidade.

O significado das razões dessas duas forças, negativa e positiva, podem ser aplicadas em todos os sentidos matemáticos, lógicos e físicos, através dos números inteiros, baterias, imâs, sistemas lógicos, circuitos físicos e lógicos de como é o caso dos 
Sistemas Binários, em gráficos de propagação de ondas como aqui foi exposto, e de diversos outros tipos de aplicações, como na simetria dos seres e até nos posicionamentos geográficos dos pólos no planeta terra, e que assim em todos os exemplos aqui presentes o negativo e positivo estão sempre opostos um ao outro. $E$ não é "perpendicular ou transversal" como aqui foi questionado.

Mas em resumo, a finalidade deste estudo é questionar e confrontar todos os estudos gráficos que constam em pesquisas de como é a propagação de ondas, proporcionando uma visão gráfica atualizada de observar como as ondas negativas e positivas eletromagnéticas se propagam e se comportam. E também propor um conceito de visualizar a propagação do som através de duas ondas eletromagnéticas negativas e positivas. Além de decifrar e mostrar uma nova visão a respeito de que existem 2 Infinitos observáveis, um negativo e outro positivo, matematicamente comprovado com a lógica dos números inteiros. E provar que as ondas não são "perpendiculares ou transversais", e que sim, elas são claramente opostas, tanto aplicadas e observadas na matemática quanto na física. E assim demonstrar a relação dos 2 infinitos com a propagação de ondas eletromagnéticas.

Demonstrar que existem duas razões infinitas distintas para se identificar o que é o infinito, tanto aplicado na matemática quanto na física. Um infinito negativo oposto ao infinito positivo.

Este estudo também trouxe mais informações de como funciona os circuitos lógicos dos Sistemas Binários, mas para melhor conhecimento a respeito do tema da descoberta científica do Sistema Binário 2, o artigo esta em referências.

Esse estudo dará base para pesquisas e descobertas científicas como já aconteceu. A intenção também desse estudo é proporcionar uma nova visão gráfica de como as ondas eletromagnéticas se propagam, para que quando se pesquisar gráfico de propagação de ondas na internet, apareça esta informação que é mais precisa e atualizada de como é a propagação de ondas. 
A intenção principal deste estudo é informar. Perto da realidade, pode ser apenas um detalhe, mas se você não vê ou não enxerga direito, você não consegue calcular direito, mas vendo e enxergando melhor, se consegue calcular melhor, assim é mais fácil observar as propagações de ondas através desses gráficos expressados neste estudo.

Exemplos de gráficos que estão sendo contestados:

Gráfico 14: propagação das ondas.

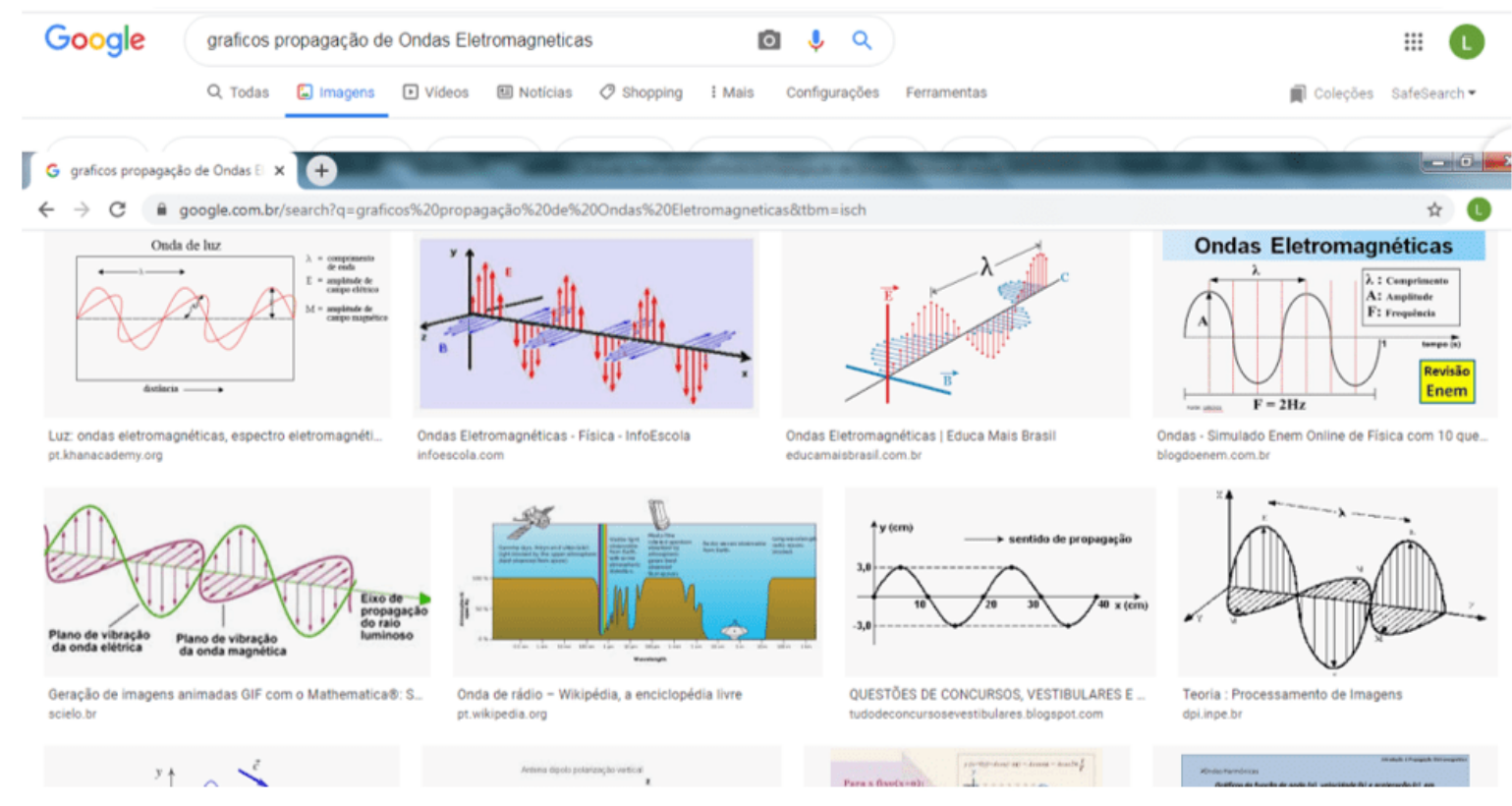

Fonte: internet Google.

Gráficos corretos de propagação de ondas:

Gráfico 15: propagação das ondas. 


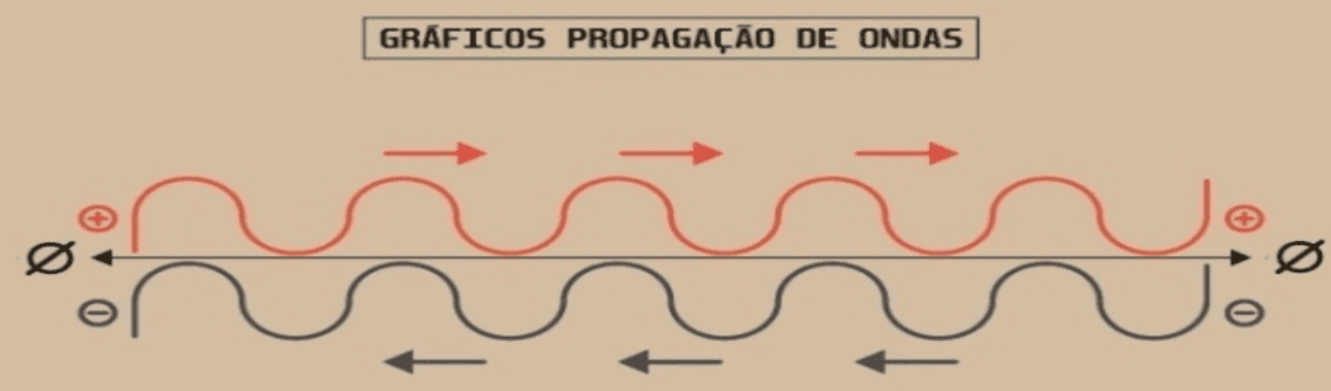

Fonte: Autor.

Gráfico 16: proporção das ondas.

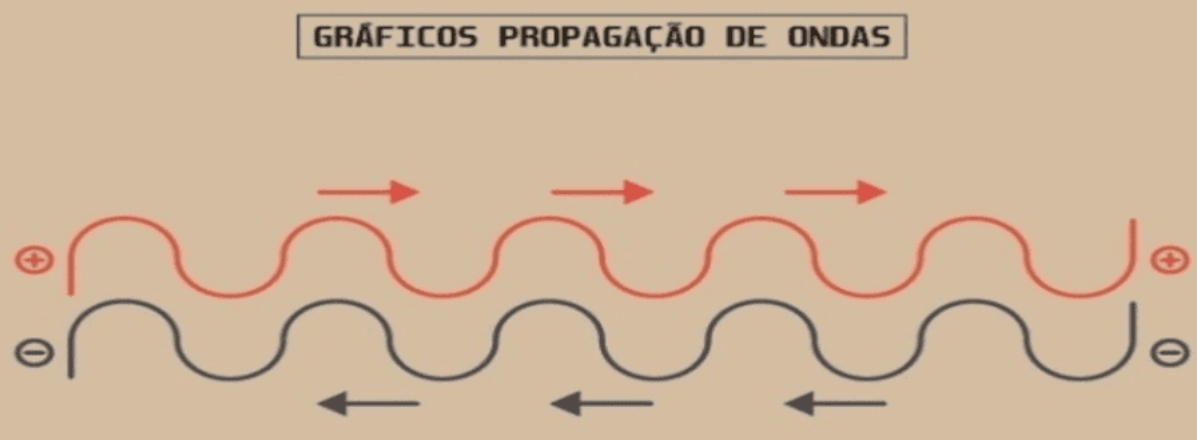

Fonte: Autor.

\section{REFERÊNCIAS}

BELLAS, L. D. Sistema binário 2 - Código Fechado. Revista Científica Multidisciplinar Núcleo do Conhecimento. Ano 04, Ed. 02, Vol. 05, pp. 110-151. Fevereiro de 2019. ISSN: 2448-0959.Disponível em: 
https://www.nucleodoconhecimento.com.br/tecnologia/sistema-binario-2-codigofechado

HELERBROCK, Rafael. Ondas Eletromagnéticas. Mundo da Educação. Disponível em: https://mundoeducacao.uol.com.br/fisica/ondaseletromagneticas.htm\#: :text=Ondas\%20eletromagn\%C3\%A9ticas\%20transportam \%20energia\%20atrav\%C3\%A9s,meio\%20material\%20para\%20propagar\%2Dse.

MAOR, ELI (1991). To infinity and beyond: a cultural history of the infinite (em inglês). Princeton, N.J.:Princeton University Press. ISBN 978-0-691-02511-7

PESQUISA

BING.:Infinito.

Disponível

em:

https://www.bing.com/search?q=infinito\&qs=HS\&pq=in\&sc=8-

2\&cvid=B59BFC32A83D4D7F81C9F0B403E7F694\&FORM=QBLH\&sp=1c

PESQUISA BING.Propagação de Ondas. Disponível em: https://www.bing.com/images/search?q=propaga\%c3\%a7ao+de+ondas\&form=HDR SC2\&first=1\&scenario=ImageBasicHover

PESQUISA GOOGLE.Propagação de Ondas. Disponível em: https://www.google.com/search?q=propaga $\% C 3 \% A 7 \% C 3 \% A 30+d e+o n d a s \& r l z=1 C 1$ CHBD_pt-PTBR903BR903\&hl=pt-

PT\&sxsrf=ALeKk01uXbcZXViGvxCkRhfYu2119_NbXQ:1593470133251\&source=Inm s\&tbm=isch\&sa=X\&ved=2ahUKEwjhILqiqjqAhVRGbkGHY4BKwQ_AUoAXoECBEQAw\&biw=1536\&bih=722

Enviado: Maio, 2020.

Aprovado: Novembro, 2020. 